\section{DNA cycle}

Passengers travelling from London to Cambridge by train may glimpse this striped cycle path cutting through the flat countryside as they near their destination. Over a mile of its length, different coloured bands spell out the base-pair sequence of the BRCA2 gene mutations in which are associated with increased risk of breast cancer. The path includes the UK cycle network's ten thousandth mile. John Sulston, director of the Cambridge Sanger Centre during its work on the Human Genome Project, and a keen cyclist, helped develop the idea of decorating it with a gene.

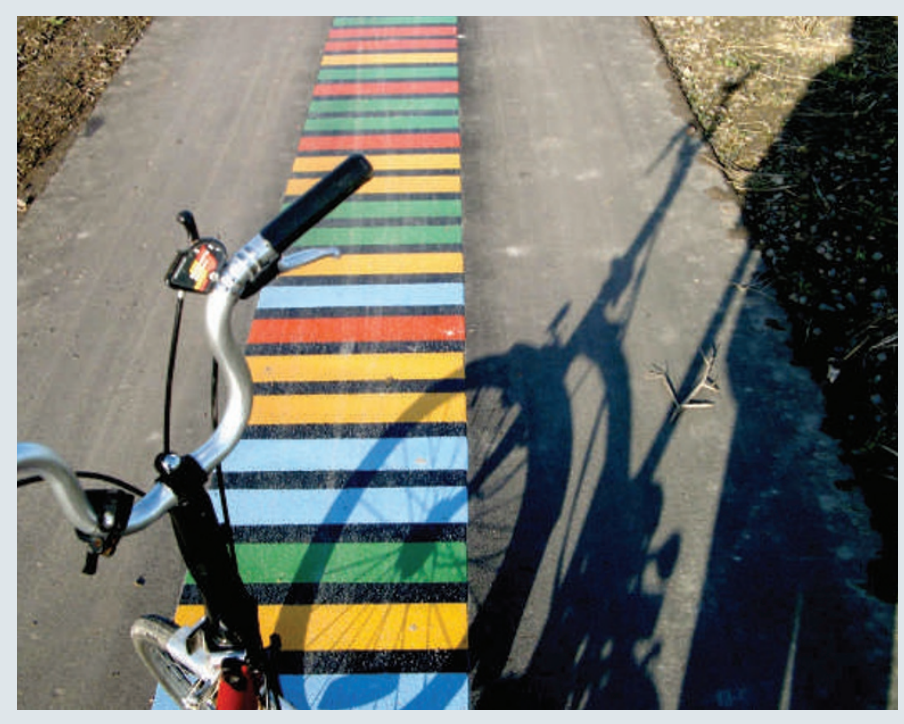

BRCA2 was picked because the gene contains about 10,000 base pairs, echoing the cycle network's celebratory theme. But there were other reasons, too. As a predictor of disease and the subject of a patent dispute, BRCA2 highlights some of the social issues that surround gene sequencing.

"I expect this will be one of only a few human genes to be represented as a cycle path," says Michael Stratton, who identified and mapped BRCA2 twelve years ago and acted as a scientific advisor to this project. It's a safe bet - were the entire human genome laid down at the same scale, the path would circle Earth about ten times.

J.H.

\title{
A golden circle in the sky
}

\section{An Ocean of Air : A Natural History of the Atmosphere \\ by Gabrielle Walker \\ Bloomsbury/Harcourt: 2007. 321 pp. E15.99/\$25.}

\section{Raymond T. Pierrehumbert}

For its passengers stopping over in Reykjavik, IcelandAir offers a one-day Golden Circle Tour of the principal sights - an hour at Thingvellir, a photo-stop at Dettifoss, enough time at Geysir to at least see Strokkur let loose, if not the old girl herself, and so forth. It's not a great way to see Iceland, but it gives travellers some impression of the wonders of the place. Gabrielle Walker's grand tour of Earth's atmosphere is very similar, although without the obligatory stop at the souvenir shop.

An Ocean of Air is at once better and worse than IcelandAir's tour. First, the good: Walker has a fine facility with words, and paints a thrilling picture of the grand sweep of atmospheric science and the parade of great minds and key experiments that led us to where we are today. Although there is little here that is not already accessible in other popular science writing, such as Lucy Jago's magnificent The Northern Lights (Hamish Hamilton, 2001), the way Walker assembles the collage is an achievement. Even if you know the territory well, it adds a lot to see the whole story laid out compactly with so much enriching historical and biographical detail.

However, although the Golden Circle tour guides may not tell you much, what they do tell you is generally true. The same, alas, cannot be said for Walker. I became suspicious in the first chapter, dealing with Galileo's determination of the weight of air. Walker starts well enough, discussing Galileo's pathbreaking experiments in weighing compressed air in a bottle, but then declares that he believed that air became weightless when returned to its proper place, the sky, making him out to be some kind of neo-Aristotelian.

Could the father to the Renaissance rebirth of hydraulics really have been so misguided? Well, no, it turns out. In the section of the Dialogo dealing with these experiments, it is clear that Galileo is talking about Archimedes' principle. The flaw in his reasoning is more subtle and interesting, arising from Galileo's ignorance of what we would now call Newton's Third Law, of reciprocal actions. A bit of air in the atmosphere is made neutrally buoyant because the bit of air below pushes up on it so as to cancel its weight. But that means the air being held up pushes back on the air below, which must in turn push on what's below it, and so forth, until finally it can exert a force on a solid surface, or on water being pushed through a siphon.

This may seem an academic point, but one reads a popular science book not just for entertainment, but for illumination. If it leaves the reader with misconceptions, one might as well be reading science fiction instead. And there are lots of misconceptions here. Walker tells us that breathing pure oxygen would be fatal. It's not, and astronauts used to do it all the time; you can breath pure oxygen more or less indefinitely without harm, as long as the pressure is low enough.

She also tells us that Fourier computed what Earth's temperature would be without an atmosphere, and found it to be far colder than it actually is. Fourier did no such thing, and could not have with the tools of his time. By repeating this urban legend from secondary sources rather than delving into Fourier's writings, she misses the story of his remarkable, genuine contribution to our understanding of Earth's energy balance (see Nature 432, 677; 2004).

Walker says that Gilbert Plass restored concern about $\mathrm{CO}_{2}$ and global warming by showing that its absorption bands are saturated (absorbing as much infrared as they can, so that addition of more $\mathrm{CO}_{2}$ causes no more absorption) only at sea level, not at upper atmospheric pressures. There is indeed a story to be told about the 50-year struggle to understand how radiation travels through the atmosphere, but this isn't it. Carbon dioxide absorption is not saturated at sea level, and would not be even if the $\mathrm{CO}_{2}$ content were 10,000 times greater than today. The real problem with the prevailing conception of the greenhouse effect had more to do with a failure to appreciate the role of cold air aloft, and little to do with either pressure broadening or band saturation.

And when it comes to long-term $\mathrm{CO}_{2}$ changes, Walker spins a fanciful yarn around a highly speculative theory involving dinosaurs' supposed ability to digest lignin in wood (they almost certainly couldn't), rather than discussing the well-established role of the formation of limestone by silicate weathering. There is so much sloppiness of this sort that when, at the end of the book, Walker informs us that the Inuit of Greenland are unconcerned about global warming because they are hunters, not farmers, we hardly flinch.

She stops short of some of the exciting current research - notably the role of the exosphere in hydrogen escape from the atmosphere, which has profound implications for the origins of life - but the main problem is what she gets wrong, not what she leaves out. The too often lackadaisical research is a real pity. Read this book for the grand sweep of history, but keep your Web browser and library card handy to sort out which bits to believe. Raymond T. Pierrehumbert is Louis Block

Professor in the Geophysical Sciences, the University of Chicago, 5734 South Ellis Avenue, Chicago, Illinois 60637, USA. 